\title{
MANAGERIAL INCENTIVES AND FINANCIAL SIGNALING IN PRODUCT MARKET COMPETITION*
}

\author{
Jacob GLAZER \\ Boston University, Boston, MA 02215, USA \\ Ronen ISRAEL \\ The University of Michigan, Ann Arbor, MI 48109, USA \\ Final version received July 1989
}

This paper demonstrates how management compensation schemes can serve as an inexpensive and sometimes even free signaling mechanism. In the particular example studied here it is shown how a contract offered to the manager of a monopolistic firm may induce him to take some actions that will credibly signal the firm's marginal cost and will deter entry if the firm is 'sufficiently' efficient. This signaling mechanism is not costly to the monopolist and therefore, it may prefer this mechanism to the costlier 'limit pricing' one.

\section{Introduction}

In their seminal paper, Milgrom and Roberts (MR) (1982) were able to rehabilitate the old notion of 'limit pricing' and to show that in the case of asymmetric information a monopolist may, indeed, charge a price lower than its monopoly price just in order to signal some private information to a potential entrant and by so doing deter entry. The importance of this result is that it shows that the threat of entry alone is, sometimes, enough to eliminate some of the welfare distortions created by a monopolist. The limit pricing' signaling mechanism, however, is costly to the monopolist, since its profit during the pre-entry decision period may be well below the monopolistic one. The question that comes up is, therefore, whether there are other less costly signaling mechanisms that the monopolist can use in order to deter entry. The purpose of our paper is to show that alternative, less costly, signaling mechanisms do exist and 'limit pricing' may not be such a widespread phenomenon after all.

\footnotetext{
*We wish to thank Kyle Bagwell, Michael J. Fishman, John Panzar, Robert Porter, Daniel R. Siegel, and three anonymous reviewers for helpful comments. Special thanks are due to Robert T. Masson for helpful comments and in particular for pointing out to us the relevance of the SEC law to our model. All remaining errors are, of course, ours.
} 
We show that 'appropriately' constructed management compensation schemes can serve as an inexpensive signaling mechanism in product market competition. Management compensation schemes are an especially convenient signaling mechanism. A firm could select in year $t$ to pay its executive(s) a deferred stock bonus equal to some number in year $t+\tau$. By SEC law this contract must be reported publicly in the firm's proxy statement. Such a contract is enforceable. Unpublished side agreements designed to circumvent the published agreements would not only be legally unenforceable, but in violation of SEC law.

In our model the manager of a monopolistic firm privately observes the firm's marginal cost. Another firm (the entrant) is considering entry into the monopolist's market. It is common knowledge that entry will be profitable to the entrant if and only if the monopolist's marginal cost is high. MR have shown that, in such a case, the monopolist can use prices as a signaling device that will deter entry. By charging a 'sufficiently' low price the monopolist can 'prove' its low cost and the potential entrant stays out. In this paper we show that, instead, the owners of the monopolistic firm can offer the manager a compensation scheme that will induce him, in equilibrium, to change the firm's capital structure by substituting equity for debt if and only if the firm's marginal cost is low. Along this equilibrium the potential entrant enters unless the monopolist changes its capital structure. This signaling mechanism is shown to be very inexpensive and sometimes even free.

In our model, the signal is induced by the manager's compensation scheme and transmitted via the firm's financial action. It should be mentioned, however, that this paper does not aim to explain capital structure and this was chosen simply as one example of how the mechanism might work.

Following MR, many researchers have addressed the issue of signaling in product market competition. Among them are Matthews and Mirman (1983) and Saloner (1984). The question of financial actions as a signaling device have been studied by, among others, Bhattacharya $(1979,1980)$, Leland and Pyle (1977) and Ross (1977, 1979), and in the context of product market competition by Bhattacharya and Ritter (1983), Gertner, Gibbons and Scharfstein (1988) and Maksimovic (1988). These papers, however, focus on one signaling mechanism and the question of the cost of this mechanism relative to alternative mechanisms is not addressed. The cost of the mechanism is precisely the focus of our paper since we show that management compensation schemes are, sometimes, the cheapest signaling device available to the firm.

Our paper is also related to the area of research that studies ownermanager contracts and particularly to Ross (1977). Ross (1977) has shown how shareholders, by offering their manager an appropriate compensation scheme, may create a financial signaling mechanism in the capital market. 
The crucial element in this incentive scheme is that managers are severely punished in the case of bankruptcy. The incentive scheme offered in our paper is very different and bankruptcy does not play any role in it. Fershtman and Judd (1987) study equilibrium incentive schemes in oligopoly. Their work does not consider financial decisions and signaling effects.

Other, non-signaling, papers that have studied the relationship between product market competition and financial actions are Allen (1985), Brander and Lewis (1986), and Maksimovic (1986).

The rest of the paper is organized as follows: Section 2.1 describes the environment and section 2.2. describes the manager's contract. In section 3 the manager-entrant game is defined, and in section 4 the entry deterring signaling equilibrium is presented. Section 5 discusses the cost of the mechanism to the signaling firm and our conclusions are given in section 6 .

\subsection{The enïronment}

A monopolist $M$ operates in a market with inverse demand $P=p(X)$. There are two periods in the model, 0 and 1 . At the beginning of period 0 the monopolist is engaged in an innovation process in an attempt to reduce the firm's constant marginal cost. The innovation process is uncertain and it is common knowledge that the monopolist's post innovation marginal cost $C^{M}$ is distributed as follows:

$$
C^{M}=\left\{\begin{array}{l}
\bar{C} \text { with probability } 1-q \\
C \text { with probability } q,
\end{array}\right.
$$

where $\bar{C}>C$. At the end of period 0 the manager of firm $M$ privately learns whether the firm's marginal cost is $\underline{C}$ or $\bar{C}$.

At the beginning of period 1 a second firm $E$ is deciding whether or not to enter the monopolist's market. When making this decision, firm $E$ does not know firm $M$ 's constant marginal cost and its prior beliefs are distributed according to (1). It is common knowledge that firm $E$ 's constant marginal cost is $C^{E}{ }^{1}$ If firm $E$ enters, then it will observe firm $M$ 's marginal cost and the two firms will compete in some duopolistic fashion. ${ }^{2}$ It is assumed that in the case of entry, firm $M$ 's profit will be $\pi^{M}\left(C^{M}, C^{E}\right)$ where $C^{M}$ is either $\bar{C}$ or $C$ and firm $E^{\prime}$ 's net profit will be $\pi^{E}\left(C^{E}, C^{M}, K\right)$ where $K$ is firm $E^{\prime}$ 's entry cost. If, however, firm $E$ decides not to enter, firm $M$ will collect the monopolist's profit $\pi^{M}\left(C^{M}\right)$ and firm $E$ 's profit will be zero. We make the following assumption:

\footnotetext{
${ }^{1}$ The model can be easily extended to the case where $C^{E}$ is stochastic and is unknown to firm M.

${ }^{2}$ The assumption that $C^{M}$ becomes common knowledge after firm $E$ enters is made in order to simplify the analysis. It is by no means essential for our main arguments to hold.
} 


\section{Assumption 1.}

(a) $\pi^{M}(\underline{C})>\pi^{M}(\bar{C})$,

(b) $\pi^{M}\left(\underline{C}, C^{E}\right)>\pi^{M}\left(\bar{C}, C^{E}\right)>0$

(c) $\pi^{M}\left(C^{M}\right)>\pi^{M}\left(C^{M}, C^{E}\right)$ for $C^{M}=\bar{C}$ or $C$,

(d) $\pi^{E}\left(C^{E}, \bar{C}, K\right)>\pi^{E}\left(C^{E}, \subseteq, K\right)$.

Parts (a) and (b) of Assumption 1 simply state that firm $M$ 's profit is a decreasing function of its own marginal cost. Part (c) states that firm $M$ 's profit as a monopolist is higher than its profit as a duopolist. Part (d).states that entry is more profitable to firm $E$ the higher is the marginal cost of firm $M$. Therefore if $\pi^{E}\left(C^{E}, C, K\right)>0$ then, regardless of the realization of $C^{M}$, entry will be profitable for firm $E$, and if $\pi^{E}\left(C^{E}, \bar{C}, K\right)<0$ then, regardless of the realization of $C^{M}$, entry will not be profitable for this firm. In the case in which $\pi^{E}\left(C^{E}, \bar{C}, K\right) \geqq 0$ but $\pi^{E}\left(C^{E}, C, K\right)<0$, entry will be profitable for firm $E$ only if firm $M$ failed with the innovation. This last case is the focus of our paper since it is here where the unobservability of $C^{M}$ by firm $E$ (when making its entry decision) is important. This is also the case in which firm $M$, if it succeeds with the innovation, will try to 'convince' firm $E$ that its marginal cost is actually $\underline{C}$ and therefore it should not enter. In order to do so, firm $M$ can offer its manager (who privately observes the firm's marginal cost realization) a particular compensation scheme of the form discussed in the following section.

\subsection{The manager's contract}

In order to simplify the analysis let us assume that the manager of firm $M$ is risk neutral. In section 5 the effects of dropping this assumption will be discussed. Suppose that at the beginning of period 0 the manager of firm $M$ is offered a compensation scheme $W=\left(W_{0}, \gamma_{1}\right)$ where $W_{0}$ is a lump sum that the manager gets at the beginning of period 0 and $0<\gamma_{1}<1$ is a fraction of the firm's equity that the manager will get at the end of period 1 after firm $E$ announces whether it enters. It is assumed that the compensation scheme $W=\left(W_{0}, \gamma_{1}\right)$ is common knowledge to all agents in our model and in particular known by firm $E$. Also it is common knowledge that the manager is not allowed to buy or sell any of the firm's stock. After it collects its profits at the end of period 1 , firm $M$ will be liquidated. ${ }^{3}$

Suppose that at the end of period 0 , after privately observing its firm's marginal cost, the manager of firm $M$ is allowed to conduct the following change in the firm's financial structure: He can issue debt with a face value of $F$ dollars and immediately pay all the money raised as a dividend to the

${ }^{3}$ This assumption is not necessary and it is made in order to simplify the analysis. 
firm's shareholders. It is assumed that $F$ as well as the dividend payments are observable by firm $E$.

Let $V$ denote the value of firm $M$ at the end of period 1 . Then,

$$
V=\left[\begin{array}{ll}
\pi^{M}\left(C^{M}\right) & \text { if } E \text { does not enter } \\
\pi^{M}\left(C^{M}, C^{E}\right) & \text { if } E \text { enters. }
\end{array}\right.
$$

The debtholders' claim at the end of period 1 will be

$$
D=\min \{F, V\} .
$$

Although we assume a limited liability of the firm, it will be clear later that the manager does not have any incentives to default on the debtholders. It will be shown that bankruptcy never occurs in equilibrium and therefore the firm only pays the risk-free interest rate on this debt. The risk-free interest rate is normalized in our model to be zero. This normalization is inessential to any of our results.

The equity value at the end of period 1 will be:

$$
S=V-D \text {. }
$$

Thus, the total payment earned by the manager of firm $M$ according to the compensation scheme $W=\left(W_{0}, \gamma_{1}\right)$ will be

$$
\bar{W}=W_{0}+\gamma_{1} S .
$$

There are two facts to observe regarding $\bar{W}$. First, $\bar{W}$ is decreasing with $F$. This is true since the more debt is issued, the smaller is the proportion of equity in the total value of the firm and hence the smaller is the fraction that the manager receives from the firm's value. Second, $\bar{W}$ is smaller if firm $E$ enters than if firm $E$ does not enter. This is true since the value of firm $M$ 's equity (and hence the manager's fraction of it) at the end of period 1 is increasing with the firm's profits. Therefore the manager would not like to issue debt unless by doing so he could somehow deter entry and increase the overall value of $\bar{W}$. In the signaling game studied below, the decrease in $\bar{W}$, which results from the issuance of debt, will represent the 'signaling-cost' of the manager of firm $M$, and the increase of $\bar{W}$, which results from deterring entry, will represent his 'signaling-payoff'.

\section{The manager-entrant game}

In this section it will be assumed that $W=\left(W_{0}, \gamma_{1}\right)$ is given, and the interaction between firm $E$ and the manager of firm $M$ will be studied. This 
interaction (game) will be defined by a pair of strategies and their associated payoffs to firm $E$ and the manager of firm $M$.

\section{Definition 1.}

(a) A strategy for the manager of firm $M$ is a function $f:\{\underline{C}, \vec{C}) \rightarrow R_{+}$such that $f\left(C^{M}\right)=F$ specifies the face value of firm $M$ 's debt as a function of its realized marginal cost.

(b) A strategy for firm $E$ is a function $g: R_{+} \rightarrow\{e, n\}$ such that $g(F)$ specifies firm $E$ 's entry decision as a function of the face value $F$ of firm $M$ 's debt, and where $e$ stands for 'enter' and $n$ stands for 'do not enter'.

(c) The payoff to the manager of firm $M$ is a function $\bar{w}:\{C, \bar{C}\} \times R_{+} \times\{e, n\}$ $\rightarrow R_{+}$such that:

$$
\begin{aligned}
& \bar{w}\left(C^{M}, F, e\right)=W_{0}+\gamma_{1} \max \left\{\pi^{M}\left(C^{M}, C^{E}\right)-F, 0\right\}, \quad \text { and } \\
& \bar{w}\left(C^{M}, F, n\right)=W_{0}+\gamma_{1} \max \left(\pi^{M}\left(C^{M}\right)-F, 0\right\} .
\end{aligned}
$$

(d) The payoff to firm $E$ is a function $u:\{e, n\} \times\{\underline{C}, \bar{C}\} \rightarrow R_{+}$such that:

$$
\begin{aligned}
& u\left(e, C^{M}\right)=\pi^{E}\left(C^{E}, C^{M}, K\right), \quad \text { and } \\
& u\left(n, C^{M}\right)=0 .
\end{aligned}
$$

Next we define an entry deterring signaling equilibrium.

\section{The entry deterring signaling equilibrium}

Definition 2. An entry deterring signaling equilibrium is a pair of strategies $\left(f^{*}, g^{*}\right)$ such that:

(a) $f^{*}(C)=F^{*}>0$,

$$
f^{*}(\bar{C})=0 \text {, }
$$

(b) $g^{*}(F)= \begin{cases}n & \text { if } F \geqq F^{*} \\ e & \text { if } F<F^{*},\end{cases}$

(c) $\bar{w}\left(\underline{C}, F^{*}, n\right)>\bar{w}(\underline{C}, 0, e)$,

$$
\bar{w}(\bar{C}, 0, e)=\bar{w}\left(\bar{C}, F^{*}, n\right),
$$

(d) $u(e, \mathscr{C})<0$,

$$
u(e, \bar{C}) \geqq 0 \text {. }
$$

It can be seen that our definition of entry deterring signaling equilibrium is 
somewhat more restrictive than the usual signaling-Nash equilibrium. We not only require that the strategies $f^{*}$ and $g^{*}$ will be best-responses to each other, but also that they constitute the 'less costly' separating equilibrium, from the manager's point of view. This is the reason for the equality (instead of inequality) condition in the second part of (c). This equality means that $F^{*}$ is the smallest $F$ that constitutes a signaling-Nash equilibrium. This type of equilibrium is also the one studied primarily in Milgrom and Roberts (1982). ${ }^{4}$

The following proposition characterizes the conditions under which an entry deterring signaling equilibrium exists. It is also shown that this equilibrium is unique.

Proposition 1. (a) If

$$
\begin{aligned}
& \pi^{M}(\underline{C})-\pi^{M}\left(C, C^{E}\right)>\pi^{M}(\bar{C})-\pi^{M}\left(\widetilde{C}, C^{E}\right), \quad \text { and. } \\
& \pi^{E}\left(C^{E}, \bar{C}, K\right) \geqq 0 \quad \text { but } \quad \pi^{E}\left(C^{E}, \underline{C}, K\right)<0,
\end{aligned}
$$

then there exists an entry deterring signaling equilibrium.

(b) If an equilibrium exists then it is unique and:

$$
F^{*}=\pi^{M}(\bar{C})-\pi^{M}\left(\bar{C}, C^{E}\right)
$$

Proof. (a) (10) follows from substituting (6) and (7) into Definition 2(c) and (11) follows from substituting (8) and (9) into Definition 2(d).

(b) Follows from substituting (6) and (7) into the equation given in the second part of Definition 2(c). Q.E.D.

The manager-entrant game described above also possesses pooling equilibria. In order to see what happens along this equilibria one should distinguish between two cases:

Case 1. The entrant's expected profits are negative, i.e.:

$$
q \pi^{E}\left(C^{E}, C, K\right)+(1-q) \pi^{E}\left(C^{E}, \bar{C}, K\right)<0 .
$$

Case 2. The entrant's expected profits are non-negative, i.e.:

$$
q \pi^{E}\left(C^{E}, \underline{C}, K\right)+(1-q) \pi^{E}\left(C^{E}, \bar{C}, K\right) \geqq 0 .
$$

\footnotetext{
${ }^{4}$ The entry deterring signaling equilibrium is also the unique separating Nash equilibrium that is not rejected by the intuitive criterion developed in Cho and Kreps (1987) and is the unique Grossman and Perry (1986) perfect sequential equilibrium.
} 
In case 1 there is a continuum of pooling equilibria along which the monopolist, regardless of its marginal cost realization, issues a debt level $F \geqq 0$ and the entrant does not enter. In this case, however, there is no incentive for the owners of firm $M$ to offer the manager a contract $\left(W_{0}, \gamma_{1}\right)$ with $\gamma_{1}>0$ since signaling does not take place. In case 2 there exists only one pooling equilibrium along which firm $M$, regardless of its marginal cost realization, does not issue any debt and firm $E$ enters. This equilibrium, however, does not satisfy the intuitive criterion, developed in Cho and Kreps (1987), and the only equilibrium that does is the separating one.

\section{The cost of the mechanism}

Suppose that the conditions for the separating equilibrium as stated in Proposition 1(a) hold. The question remaining is: What is the cost of implementing this entry deterring signaling mechanism to (the owners of) firm $M$ ? Two sorts of cost could be associated with this mechanism: One is a cost that might follow from the debt issued and the other is a cost that might follow from the special compensation scheme offered to the manager. The debt issued would have been costly for the firm had there been some bankruptcy costs associated with it. This, however, is not the case in our model since bankruptcy can never occur in equilibrium. In order to see why, notice that firm $M$ issues debt only when $C^{M}=C$, and in such a case the size of the debt, $F^{*}$, is always smaller than the firm's profit $\pi^{M}(\underline{C})$. This is true since:

$$
\begin{aligned}
F^{*} & =\pi^{M}(\bar{C})-\pi^{M}\left(\bar{C}, C^{E}\right)(\text { by Proposition } l(b)), \\
& <\pi^{M}(\bar{C}), \\
& <\pi^{M}(\underline{C})(\text { by Assumption } I(a)) .
\end{aligned}
$$

Therefore, the firm will always have enough profit to cover its debt and bankruptcy cannot occur.

In order to see the cost to the firm that follows from the special compensation scheme offered to the manager let us assume that the manager's reservation wage for the two periods combined is $W^{R}$. It is clear that, if the manager is risk neutral, the firm does not have to bear any cost in implementing our mechanism since it can always offer the manager a compensation scheme $\left(W_{0}, \gamma_{1}\right)$ such that:

$$
W_{0}+\gamma_{1}\left[(1-q) \pi^{M}\left(\bar{C}, C^{E}\right)+q\left(\pi^{M}(C)-F^{*}\right)\right]=W^{R} .
$$

In the case of risk aversion the firm has to bear some cost in order to 
implement the entry deterring signaling mechanism. This cost, however, can be made small by, for example, offering the manager a compensation scheme $\left(W_{0}, \gamma_{1}\right)$ such that $W_{0}=W^{R}$ and $\gamma_{1}$ is strictly positive but close to zero. This compensation scheme is certainly enough to keep the manager in the firm and it is also enough (as long as $\gamma_{1}$ is strictly positive) to create the 'right' incentives.

\section{Discussion and conclusion}

This paper demonstrated how management compensation schemes can serve as a convenient signaling device in product market competition. A necessary condition for such a signaling device to work is that the management's contract be public and no side payments between the firm and the management can be made in private. This condition is not always satisfied. Often the Board has a great deal of discretion in compensation setting, and even reasonably large shareholders may only see the result, ex post. However, as we have already mentioned in the introduction, the firm can make its management compensation scheme a credible signal by freeriding the SEC law: the firm can lock itself in to a future equity payment by invoking a deferred compensation clause. This must be made public by law (proxy statement 10-k). This raises the question whether there are other situations in which firms can free-ride this or other SEC laws and use it for their own benefit.

\section{References}

Allen, F., 1985, Capital structure and imperfect competition in product markets, Lniversity of Pennsylvania, Mimeo.

Bhattacharya, S., 1979, Imperfect information, dividend policy, and the bird in the hand fallacy, Bell Journal of Economics 10, no. 1, 259-270.

Bhattacharya, S., 1980, Nundissipative signaling structures and dividend policy, Quarterly Journal of Economics 95, no. 1, 1-24.

Bhattacharya, S. and J. Ritter, 1983, Innovation and communication: Signaling with partial disclosure, Review of Economic Studies 50, 331-346.

Brander, James A. and Tracy R. Lewis, 1986, Oligopoly and financial structure: The limited liability effect, American Economic Review 76, no. 5, 956-970.

Cho, I. and D. Kreps, 1987, Signaling games and stable equilibria, Quarterly Journal of Economics 102, 179-221.

Fershtman, C. and K.L. Judd, 1987, Inventive equilibrium in oligopoly, American Economic Review 77, no. 5, 927-940.

Gertner, R., R. Gibbons and D. Scharfstein, 1988, Simultaneous signaling to the capital and product markets, Rand Journal of Economics 19, no. 2, 173-190.

Grossman, S. and M. Perry, 1986, Perfect sequential equilibrium, Journal of Economic Theory 39, no. 1, 97-119.

Leland, $H$. and D. Pyle, 1977. Information asymmetries. financial structure. and financial intermediation, Journal of Finance 32, no. 2, 371-387.

Maksimovic, V., 1986, Oligopoly, price wars and bankruptcy, University of British Columbia, Working paper. 
Maksimovic, V., 1988, Capital structure in repeated oligopolies, Rand Journal of Economics 19. no. 3, 389-407.

Matthews, S. and L. Mirman, 1983, Equilibrium limit pricing: The effects of private information and stochastic demand, Econometrica 51, no. 4, 981-995.

Milgrom, P. and J. Roberts, 1982, Limit pricing and entry under incomplete information: An equilibrium analysis. Econometrica 50, 443-460.

Ross, S.. 1977. The determination of financial structure: The incentive signaling approach, Bell Journal of Economics 8, no. 1, 23-40.

Ross. S., 1979, Disclosure regulation in financial markets: Some implications of modern signaling theory, in: F. Edwards, ed., Issues in financial regulation (McGraw-Hill, New York).

Saloner, G., 1984, Dynamic equilibrium limit pricing in an uncertain environment. M.I.T. Working paper no. 342 . 